\title{
The Influence of Parent's Socio Economic Status on Adolescents and Youths Health Risk Behaviors in Enugu Nigeria
}

\author{
Vivian Ozoemena Onukwuli \\ Department of Paediatrics, College of Medicine, University of Nigeria Enugu campus/University of Nigeria Teaching Hospital, Ituku/Ozalla, \\ Enugu
}

Email address:

vivianonukwuli@yahoo.com, vivian.onukwuli@unn.edu.ng

\section{To cite this article:}

Vivian Ozoemena Onukwuli. The Influence of Parent's Socio Economic Status on Adolescents and Youths Health Risk Behaviors in Enugu Nigeria. Science Journal of Clinical Medicine. Vol. 8, No. 4, 2019, pp. 33-38. doi: 10.11648/j.sjcm.20190804.11

Received: July 12, 2019; Accepted: August 4, 2019; Published: August 15, 2019

\begin{abstract}
Risk behaviors among the youth are associated with considerable negative health and developmental outcomes. The aim of the study was to examine the relationship between parent's socioeconomic status and the risk behaviors practiced by adolescents and youths in Enugu. It was a cross-sectional descriptive study. Data was collected from students in 2 tertiary institutions, who were selected consecutively using semi- structured interviewer administered questionnaire. Data was analysed using SPSS version 20.0. The level of statistical significance was set at $\mathrm{p}<0.05$. There was a high prevalence of priority health risk behaviors among the adolescents and youths. 35.8\% drove recklessly, $41.2 \%$ used alcohol and $4.4 \%$ used "hard" drugs. $34.6 \%$ had unprotected sex, $18.7 \%$ smoked cigarette, $23.8 \%$ practiced unhealthy dietary behaviors while $38.1 \%$ indulged in sedentary lifestyle. Age, gender and socioeconomic class had profound influence on the practice of risk behaviors. The age range 15-24 years and the male gender were more involved. Sedentary lifestyle and unhealthy dietary habits were commoner among students from the upper socioeconomic class. Youths from all socioeconomic strata are susceptible to health risk behaviors, thus prevention efforts for these health concerns should be universal.
\end{abstract}

Keywords: Risk Behaviours, Socio Economic Status, Adolescents, Youths, Enugu

\section{Introduction}

Youth health risk behaviors are those behaviors practiced by young people that put their health at risk. Priority health risk behaviors which contribute to the leading cause of mortality and morbidity among youths and adults, are often established during youth, extend into adulthood, are inter related, and are preventable. Some of these risk behaviors include smoking, cultism, alcoholism, teenage pregnancy, self injury, teenage suicide, domestic violence, child sexual abuse, panic disorder, eating disorder, social phobia, sexual violence, rape, sexual addiction, drug abuse, drug addiction. These risk behaviors contribute markedly to the leading causes of death, disability and social problems among youths and adults. [1]

Socioeconomic status is the relative position or standing of someone in the society in relation to his social, economic or educational attainment. Nigeria's population is predominantly young. The estimated median age is 17.4 years and about $63 \%$ of the population is less than 25 years. [2]

Adolescent is a developmental period characterized by rapid physical, psychological, social/cultural and cognitive changes. Unfortunately this is a period fraught with many threats to health and well-being in which many suffer substantial impairment and disability. [3] Although many adolescents navigate the sometimes turbulent course from childhood to adulthood to become productive and healthy adults, there is growing concern that far too many others may not achieve their full potential. Many adolescents today and perhaps increasing numbers in the years to come are at risk for adverse health outcome stemming from their behaviors. Contemporary threats to adolescent health are primarily the consequence of risk behaviors and related outcome.

Alcohol consumption is a leading contributor to accidents, homicides and suicides, the three leading causes of teen 
death. Youth who drink are more likely to have unplanned and unprotected sexual intercourse. [4] Young people are trying illicit drugs at early ages with almost one in three individuals having first experimented with alcohol (other than a few sips) before the age of 13 years. [5]

Cigarette smoking is the primary preventable cause of death in the United States. The majority of all American adult deaths results from cardiovascular disease and cancer, with many of the associated risk factors being initiated during adolescence. [3] Smoking has numerous negative effect such as lung cancer, other cancers, shorter life span, low birth weight, prematurity, higher perinatal mortality and more labour complications. [4] In Nigeria, smoking was once predominantly a male habit, but is now increasing quickly among women [4] most smokers first begin their habit when less than 18 years. One in five youths has smoked a whole cigarette and one in ten youths has tried marijuana before turning 13 years of age. [5] Substance abuse and other health risk behaviors carry an enormous price tag in terms of the toll on life, quality of life and economic costs. Drug use results in rising number of patients in mental hospitals and treatment centers. A particular concern of drug use is transmission of HIV and hepatitis B via needles [4] Poor dietary behaviors and high rate of physical inactivity contribute to obesity with a potential complication of type II diabetes mellitus. This may further result in cardiovascular diseases, kidney failure and blindness. Besides these, overweight and obese children and adolescents are at risk of becoming overweight adults with problems of coronary artery disease, hypertension, stroke, respiratory problems, gall bladder disease, osteoarthritis, sleep apnoea and some forms of cancer. Obese individuals also face decreased productivity, social stigmatization, high health care costs and premature death. Youths in our country are increasingly linked to risky sexual behavior such as casual sex and keeping of multiple sexual partners. [2] Such behaviors portend grave implications for reproductive health and reports on the current situation in the country are hardly optimistic. No other single age group sustains the negative health outcomes from their sexual behaviors as do adolescents 10 to 19 years of age [6] Early onset of sexual intercourse is associated with increased lifetime prevalence of sexual partners thereby increasing the risk of exposure to sexually transmitted diseases including HIV/AIDS, unwanted pregnancy and risk of human papilloma virus infection, due to cervical immaturity, and thus the risk of cervical cancer $[6,7]$. Many of the health risk behaviors of the $21^{\text {st }}$ century result from voluntary behaviors. They were once considered the result of faulty decision making but are now recognized as dynamic conditions (some with genetic predisposition) evolving across the lifespan. [8]

Some research has been done to document various types of health risk behaviors but few had focused on understanding the mechanisms and contextual factors responsible for the process of behavior change. Few studies to date have addressed these issues in the study environment. Understanding factors that influence youth's decision to indulge in risky behaviors will inform prevention and intervention strategies and subsequently reduce unintentional injuries and death.

\section{Methods}

\subsection{Study Area}

The study was carried out in two of the three main tertiary institutions in Enugu, the capital city of Enugu state, South East Nigeria. They are: University of Nigeria, Enugu Campus (UNEC) and institute of management and Technology (IMT). The two institutions are located close to each other in the central urban part of the Town. They are co-educational and they provide accommodation facilities for the majority of the students. Very few students attend the schools from their homes. Each of the two institutions has a student enrollment of over 10,000 undergraduates, in different faculties and departments. The students are drawn from the various states of the federation. There is a high rate of interaction between the students in these schools both in academic and extra-curricular activities in a bid to develop their personalities to a high level.

\subsection{Study Design}

The study was a descriptive cross sectional study using representative samples of students in various faculties and departments.

\subsection{Study Population}

The study population comprised only of undergraduate students aged 15-29 years who gave consent for the study.

\subsection{Consent}

Ethical clearance was obtained from the Research and ethics committee of the UNTH Enugu. Permission was gotten from the Ministry of Education, Enugu State of Nigeria to use the schools for the study. Further permissions to use the selected students were obtained from the respective heads of the departments while assent was obtained from the adolescents and youths.

\subsection{Data Collection}

A validated pre tested interviewer administered questionnaire was used to collect data from the participants. This includes data on demographic characteristics as well as their practice of health risk behaviours.

\subsubsection{Anthropometric Measurement}

Weights were measured using standardized bathroom scale. Each measurement was recorded to the nearest 0.1 kilogram and the scale was recalibrated after every twenty measurements. Their heights were measured to the nearest $0.1 \mathrm{~cm}$, using stadiometer following standard protocols. Their body mass indices (BMI) were calculated using the formula:

$$
\mathrm{BMI}=\frac{\text { Weight in kilograms }}{{\text { (Height in metres })^{2}}^{2}}
$$




\subsubsection{Social Class Determination}

The social class of each student was determined using the method advanced by Oyedeji. [9] Here, the social class was obtained with the highest educational attainment and occupation of the mother and father combined. The average of the four scores (two each for the father and mother respectively, that is, occupational status and highest educational attainment) to the nearest whole number was assumed as the social class of each student studied. The highest score is 1 while the lowest is 5 . Social classes I and II; III; IV and V were classified as high, middle, and low socioeconomic class respectively. In situation where one of the parents is late, the social class of the surviving parent is used.

\subsubsection{Data Analysis}

The data was analysed using statistical package for social sciences (SPSS) version 20.0 Chicago Il. The level of statistical significance was set at $\mathrm{p}<0.05$.

\section{Results}

Eight hundred and sixty-one (861) students were studied. This consists of 544 males and 317 females giving a male: female ratio of 1.7: 1. Majority of the students (94.4\%) were single. Their mean body mass index was $23.31 \pm 2.57 \mathrm{~kg} / \mathrm{m}^{2}$ (Table 1).

Table 1. Demographic characteristics of the respondents.

\begin{tabular}{lll}
\hline DEMOGRAPHIC VARIABLE & FREQUENCY $(\mathbf{N}=\mathbf{8 6 1})$ & PERCENT \\
\hline Age group (years): & & \\
$15-19$ & 41 & 4.8 \\
$20-24$ & 600 & 69.7 \\
$25-29$ & 220 & 25.6 \\
Gender: & & \\
Male & 544 & 63.2 \\
Female & 317 & 36.8 \\
Marital Status: & & \\
Single & 813 & 94.4 \\
Married & 48 & 5.6 \\
Socioeconomic Status: & & 65.7 \\
Upper class & 566 & 14.4 \\
Middle class & 124 & 19.9 \\
Lower class & 171 & \\
Mean weight $(\mathrm{kg}) \pm \mathrm{SD}$ & $66.38 \pm 8.46$ & \\
Mean height $(\mathrm{m}) \pm \mathrm{SD}$ & $1.69 \pm 0.08$ & \\
Mean BMI $\left(\mathrm{kg} / \mathrm{m}^{2}\right) \pm \mathrm{SD}$ & $23.31 \pm 2.57$ & \\
\hline
\end{tabular}

The age groups 20-24 years were more involved in risky behavior. Out of 861 students that were studied, 802 (93.1\%) students were involved in at least one type of risk behavior. $59(6.9 \%)$ students were not involved in any risk behavior. $18.6 \%$ of students aged 15-19 years did not engage in any risk behavior whereas only $3.7 \%$ of students in the same age range engaged in risk behaviors. This was statistically significant. On the other hand, $28.8 \%$ of students aged $25-29$ years did not engage in any risk behavior compared with $25.3 \%$ of students in the same age range who practiced risk behaviors. However, the age range 20-24 years was most affected in the practice of risk behaviors. $71 \%$ of them were involved in risk behaviors whereas $52.5 \%$ of them did not practice any risk behavior. This was statistically significant. There were more males in both groups $513(64.0 \%)$ in the risk behavior group and $31(52.5 \%)$ in the non risk behavior group. Majority of the respondents belonged to the upper socioeconomic class both in the risk behavior group 531 $(66.2 \%)$ and non risk behavior group 35 (59.3\%). There was no significant difference in the Gender, marital status and socioeconomic class of both groups. There was significant difference between the mean weight of the risk behavior group (66.5 \pm 8.5$)$ and the non risk behavior group (64.2 \pm 7.9 ). However, there were no significant differences in the mean height and BMI of both groups. (Table 2)

Table 2. Demographic characteristics of respondents in relation to risky behavior

\begin{tabular}{|c|c|c|c|c|}
\hline \multirow{2}{*}{ DEMOGRAPHIC VARIABLE } & \multicolumn{2}{|c|}{ RISKY BEHAVIOR } & \multirow{2}{*}{ STATISTICS } & \multirow{2}{*}{ P-VAlue } \\
\hline & $\operatorname{Yes}(\%)[n=802]$ & No $(\%)[n=59]$ & & \\
\hline \multicolumn{5}{|l|}{ Age group (years): } \\
\hline $15-19$ & $30(3.7)$ & $11(18.6)$ & \multirow{2}{*}{29.413} & \multirow{2}{*}{$0.000^{*}$} \\
\hline $20-24$ & $569(71.0)$ & $31(52.5)$ & & \\
\hline $20-24$ & $569(71.0)$ & $31(52.5)$ & \multirow{2}{*}{1.915} & \multirow{2}{*}{0.166} \\
\hline $25-29$ & $203(25.3)$ & $17(28.8)$ & & \\
\hline $15-19$ & $30(3.7)$ & $11(18.6)$ & \multirow{2}{*}{13.167} & \multirow{2}{*}{$0.000^{*}$} \\
\hline $25-29$ & $203(25.3)$ & $17(28.8)$ & & \\
\hline \multicolumn{5}{|l|}{ Sex: } \\
\hline Male & $513(64.0)$ & $31(52.5)$ & \multirow{3}{*}{3.083} & \multirow{3}{*}{0.079} \\
\hline Female & $289(36.0)$ & $28(47.5)$ & & \\
\hline Marital Status: & & & & \\
\hline
\end{tabular}




\begin{tabular}{|c|c|c|c|c|}
\hline \multirow{2}{*}{ DEMOGRAPHIC VARIABLE } & \multicolumn{2}{|c|}{ RISKY BEHAVIOR } & \multirow{2}{*}{ STATISTICS } & \multirow{2}{*}{ P-VALUE } \\
\hline & $\operatorname{Yes}(\%)[\mathrm{n}=802]$ & No $(\%)[n=59]$ & & \\
\hline Single & $757(94.4)$ & $53(89.8)$ & \multirow{3}{*}{2.511} & \multirow{3}{*}{0.113} \\
\hline Married & $45(5.6)$ & $6(10.2)$ & & \\
\hline Socioeconomic Status: & & & & \\
\hline Upper class & $531(66.2)$ & $35(59.3)$ & \multirow{2}{*}{1.157} & \multirow{2}{*}{0.282} \\
\hline Lower class & $271(33.8)$ & $24(40.7)$ & & \\
\hline Mean weight $(\mathrm{kg}) \pm \mathrm{SD}$ & $66.5 \pm 8.5$ & $64.2 \pm 7.9$ & 2.031 & $0.043 *$ \\
\hline Mean height $(\mathrm{m}) \pm \mathrm{SD}$ & $1.69 \pm 0.08$ & $1.68 \pm 0.07$ & 1.160 & 0.246 \\
\hline Mean BMI $\left(\mathrm{kg} / \mathrm{m}^{2}\right) \pm \mathrm{SD}$ & $23.3 \pm 2.6$ & $22.9 \pm 2.5$ & 1.226 & 0.221 \\
\hline
\end{tabular}

*Statistically significant.

Use of alcohol has the highest prevalence of 355 (41.2\%) while use of cocaine, heroine, marijuana or other "hard" drugs has the least prevalence of $38(4.4 \%)$. (Table 3 )

Table 3. Prevalence of health risk behaviors.

\begin{tabular}{lll}
\hline HEALTH RISK BEHAVIOR & FREQUENCY (N=861) & PERCENT \\
\hline Use of alcohol & 355 & 41.2 \\
Staying idle e.g. watching films/TV, playing games for more than 4 hours in a day & 328 & 38.1 \\
Reckless driving or driving under the influence of alcohol or not wearing a helmet or seat belt when in a & 308 & 35.8 \\
car/bike & 287 & 33.3 \\
Eating too little or fasting for more than 6 hours in a day & 212 & 24.6 \\
Sex without use of productive measures e.g. condom & 205 & 23.8 \\
Eating too much especially fatty foods & 161 & 18.7 \\
Use of tobacco/cigarette & 62 & 7.2 \\
Engaging in a physical fight or other forms of violence that may result to physical injury & 38 & 4.4 \\
Use of cocaine, heroine, marijuana or other 'hard' drugs & & \\
\hline
\end{tabular}

The age group 20-24 years has the highest prevalence for all the risk behaviors except for eating too little or fasting for more than 6 hours in a day, which is more prevalent in the age group 25-29 years. This was statistically significant for use of alcohol, reckless driving, and use of tobacco. (Table 4)

Table 4. Practice of health risk behaviors in relation to age.

\begin{tabular}{|c|c|c|c|c|c|}
\hline \multirow{2}{*}{ HEALTH RISK BEHAVIOR } & \multicolumn{3}{|c|}{ AGE GROUP (YEARS) } & \multirow{2}{*}{$\mathbf{X}^{2}$} & \multirow{2}{*}{ P-VALUE } \\
\hline & $15-19(n=41)$ & $20-24(n=600)$ & $25-29(n=220)$ & & \\
\hline Use of alcohol & $8(19.5)$ & $273(45.5)$ & $74(33.6)$ & 17.731 & $0.000 *$ \\
\hline $\begin{array}{l}\text { Staying idle e.g. watching films/TV, playing games for more than } 4 \\
\text { hours in a day }\end{array}$ & $9(22.0)$ & 239 (39.9) & $80(36.5)$ & 5.578 & 0.061 \\
\hline $\begin{array}{l}\text { Reckless driving or driving under the influence of alcohol or not } \\
\text { wearing a helmet or seat belt when in a car/bike }\end{array}$ & $14(34.1)$ & $243(40.5)$ & $51(23.3)$ & 23.284 & $0.000 *$ \\
\hline Eating too little or fasting for more than 6 hours in a day & $14(34.1)$ & $185(30.8)$ & $88(40.2)$ & 6.319 & $0.042 *$ \\
\hline Eating too much especially fatty foods & $7(17.1)$ & $145(24.2)$ & $53(24.1)$ & 1.077 & 0.584 \\
\hline Use of tobacco/cigarette & $9(22.0)$ & $139(23.2)$ & $13(5.9)$ & 32.389 & $0.000 *$ \\
\hline $\begin{array}{l}\text { Engaging in a physical fight or other forms of violence that may } \\
\text { result to physical injury }\end{array}$ & $1(2.4)$ & $48(8.0)$ & $13(5.9)$ & 2.937 & 0.568 \\
\hline Use of cocaine, heroine, marijuana or other 'hard' drugs & $1(2.4)$ & $32(5.3)$ & $5(2.3)$ & 3.972 & 0.137 \\
\hline
\end{tabular}

*Statistically significant.

The following risk behaviors: use of alcohol 310 (57.0\%), reckless driving 207 (38.1\%) unprotected sex 150 (27.6\%), use of tobacco/cigarette $155(28.5 \%)$, physical fight 55 $(10.1 \%)$ and use of 'hard' drugs 37 (6.8\%) were found to be commoner in the males whereas the remaining risk behaviors were commoner in the females. All these were statistically significant $(\mathrm{P}<0.05)$ except for reckless driving. (Table 5)

Table 5. Practice of health risk behaviors in relation to gender.

\begin{tabular}{|c|c|c|c|c|}
\hline \multirow{2}{*}{ HEALTH RISK BEHAVIOR } & \multicolumn{2}{|l|}{ GENDER } & \multirow{2}{*}{$\mathbf{X}^{2}$} & \multirow{2}{*}{ P-VALUE } \\
\hline & Male $(n=544)$ & Female $(n=317)$ & & \\
\hline Use of alcohol & $310(57.0)$ & $45(14.2)$ & 151.343 & $0.000 *$ \\
\hline Staying idle e.g. watching films/TV, playing games for more than 4 hours in a day & $185(34.1)$ & $143(45.1)$ & 10.212 & $0.001 *$ \\
\hline $\begin{array}{l}\text { Reckless driving or driving under the influence of alcohol or not wearing a helmet or } \\
\text { seat belt when in a car/bike }\end{array}$ & $207(38.1)$ & $101(31.9)$ & 4.072 & 0.131 \\
\hline Eating too little or fasting for more than 6 hours in a day & $164(30.2)$ & $123(38.8)$ & 6.656 & $0.010 *$ \\
\hline Sex without use of protective measures e.g. condom & $150(27.6)$ & $62(19.6)$ & 6.933 & $0.008 *$ \\
\hline Eating too much especially fatty foods & $75(13.8)$ & $130(41.0)$ & 81.821 & $0.000 *$ \\
\hline
\end{tabular}




\begin{tabular}{|c|c|c|c|c|}
\hline \multirow{2}{*}{ HEALTH RISK BEHAVIOR } & \multicolumn{2}{|l|}{ GENDER } & \multirow{2}{*}{$\mathbf{X}^{2}$} & \multirow{2}{*}{ P-VALUE } \\
\hline & Male $(n=544)$ & Female $(n=317)$ & & \\
\hline Use of tobacco/cigarette & $155(28.5)$ & $6(1.9)$ & 94.547 & $0.000^{*}$ \\
\hline $\begin{array}{l}\text { Engaging in a physical fight or other forms of violence that may result to physical } \\
\text { injury }\end{array}$ & $55(10.1)$ & $7(2.2)$ & 20.380 & $0.000 *$ \\
\hline Use of cocaine, heroine, marijuana or other 'hard' drugs & $37(6.8)$ & $1(0.3)$ & 19.973 & $0.000^{*}$ \\
\hline
\end{tabular}

*Statistically significant.

Respondents from the upper socioeconomic class indulged more in use of alcohol $241(42.6 \%)$, staying idle 241 $(42.7 \%)$, reckless driving $216(38.3 \%)$, eating too much fatty foods $156(27.6 \%)$. Those from the middle class indulged more in eating too little $45(36.3 \%)$ while the low socioeconomic class respondents indulged more in unprotected sex 58 (33.9\%), use of tobacco/cigarette 36 (21.1\%), physical fight $22(12.9 \%)$ and use of 'hard' drugs $20(11.7 \%)$. Many of these differences were statistically significant. (Table 6)

Table 6. Practice of health risk behaviors in relation to socioeconomic status of parents.

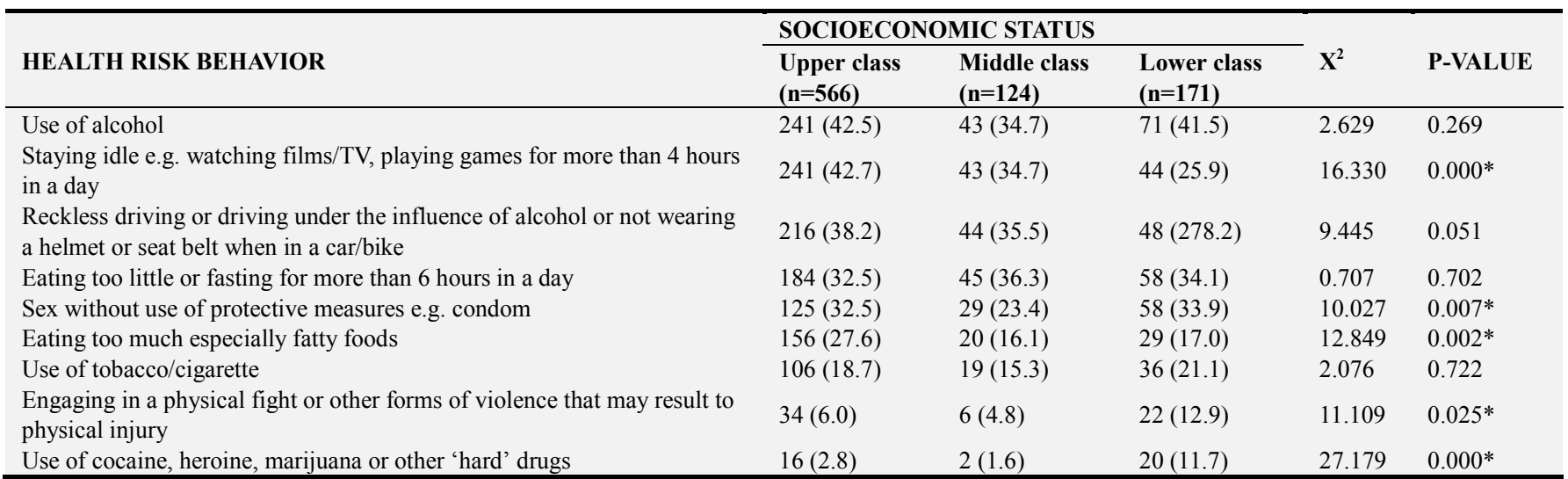

*Statistically significant.

\section{Discussion}

This study confirms substantial rate of health risk behaviors among students in tertiary institutions in Enugu. $802(93.1 \%)$ students were involved in at least one type of risk behavior whereas only $59(6.9 \%)$ students were not involved in any risk behavior. During the 3 months preceding the study, it was found that numerous youth engaged in behaviors that increase their likelihood of death. The factors noted to be associated with health risk behaviors include: age, gender, marital status, parental socioeconomic status and parental practice of same behavior. There was significant difference in the prevalence of health risk behaviors among the various age groups of the respondents. The age group 2024 years practiced most of the risk behaviors more than the other age groups. The reason is that most youths in this age range are in tertiary institutions, living away from home where parental supervision or influence may be lacking or inadequate. However, there was no significant difference in the practice of unprotected sex among the various age groups. This contradicts the finding in a Nigerian study [10] where older male and female youths were more likely to use condom protection. Significant gender difference was observed in the prevalence of health risk behaviors. Males engaged more in drug and alcohol use, reckless driving, unprotected sex, use of tobacco and cigarette as well as violent behaviors. This is similar to what was found in a Caribbean study where males also engaged more in drug and alcohol use. However, females were found to be more likely to engage in antisocial behaviors in a study done in Ibadan, Nigeria. [10] Likewise some of the risk behaviors studied like sedentary lifestyle was commoner in females. There is significant difference in the socioeconomic background of the students who practice the various types of risk behaviors.

Sedentary lifestyle and unhealthy dietary practices which predispose to overweight and obesity were found to be commoner in youths of the upper socioeconomic class. On the other hand, unprotected sex, physical violence and use of 'hard' drugs were significantly more common among those from the lower socioeconomic class. An American study [11] noted that cigarette smoking was also commoner among the lower social class which agrees with this study, whereas sedentary life style and unhealthy dietary practice were also commoner among the lower social class contradicting the finding in this study. Another study in America [12] showed that overweight which results from the two risk behaviors above was commoner among higher income households which is in keeping with the finding in this study. However, Jin-won et al in Korea [13] found an inverse association between parental SES variables and the overweight status of children and adolescents. Their method of assessment of parental socioeconomic status was subjective and this may have influenced their findings. Other studies [14, 15] showed weak relationship between socioeconomic status and risk behaviours. Parents' involvement in risky behavior did not significantly affect a youth's practice of same behavior. This 
study revealed that most risk behaviors practiced by the youth were not practiced by their parents. This contradicts an American study [16] where father's involvement predicted a reduced likelihood of subsequent engagement in risky behavior among adolescents.

A comparison between the socioeconomic class of those students who practice risky behavior and those who do not practice any risk behavior did not reveal any significant difference. $66.2 \%$ of the students, who practice risky behavior and 59.3 of those who do not practice, belonged to the upper socioeconomic class, while $19.7 \%$ of the risky group and $22.0 \%$ of the non risky group belonged to the lower socioeconomic class. Hence there is no significant difference in the socioeconomic background of students who practice and those who do not practice risky behavior. Adolescents with high aspirations of life opportunities are more likely to delay risk behavior. Therefore, efforts to reduce youth risk behaviors should move beyond the health care system and include parents, schools and communities.

\section{Conclusion}

Health risk behaviours are common among adolescents and youths in the studied area and are found among all socioeconomic classes. Thus prevention efforts for these health concerns should be universal.

\section{References}

[1] Jo Anne Grunbaum, Laura Kann, Steven A Kinchen, Barbara Williams, James G. Ross, Richard Lowry, et al. youth risk behavior Surveillance - US 2001. June 28, 2002/51 (SS 04); $1-64$.

[2] Isiugo-Abanihe UC, Male role and responsibility in fertility and reproductive health in Nigeria. Lagos Ababa press Ltd, 2003.

[3] Diclemente RJ, Hansen W, Ponton LE. Handbook of Adolescent Health Risk Behavior. New York, NY Plenum press 1966: 1-4.

[4] Igwe SA, Nigeria's Youth at Risk. African Health. 1992 May; 14 (4): 45-6.
[5] Lynne Haverkos, Louise C. Masse, Charlotte Pratt, Cherry Lowman. Understanding mechanisms of health risk behavior change in children and Adolescents. July 6, 2004. PA-04-121.

[6] Bearinger LH, Sieving RE. Global perspectives on the sexual and reproductive health of adolescents: patterns, prevention, and potentials. Lancet 2007; 369: 1220-1231.

[7] Ludicke F, Stalberg A. High and intermediate risk - human papilloma infection in sexually active adolescent females. J. pediatr. Adolesc Gynecol2001; 171-4.

[8] Nancy D. Brener, Laura Kann, steven A. Kinchen, Jo Anne Grunbaum, Laura Whalen, Danice Eaton et al. Methodology of the youth risk behavior surveillance system CDC, MMWR. September 24 2004/53 (RR 12); 1-13.

[9] Oyedeji GA, Socioeconomic and cultural background of Hospitalized Children in Ilesha. Nigerian Journal of Paediatrics 1985; 12: 111.

[10] Olley BO. Social and Health behaviors in youths of the streets of Ibadan, Nigeria. The international journal of child abuse and neglect. March 2006, P 271-282.

[11] Lowry R, Kann L, Collins JL, Kolbe LJ. The effect of socioeconomic status on chronic disease risk behavior among US adolescents. The journal of the American Medical Association vol. 276 No. 10, September 11, 1996. 12. Goodman E. the role of socioeconomic status gradients in explaining differences in US adolescents' health. Am J public health 1999; 89: 1522-1528.

[12] Jin-Won Noh, Young-eun Kim, In-Hwan OH, Young DaeKwon. Influences of socioeconomic factors on childhood and adolescent overweight by gender in Korea: cross-sectional analysis of nationally representative sample. BMC Public Health 2014; 14: 324.

[13] Ruth R Kipping, Michèle Smith, Jon Heron, Matthew Hickman, and Rona Campbell Multiple risk behaviour in adolescence and socio-economic status: findings from a UK birth cohort Eur J Public Health. 2015 Feb; 25 (1): 44-49.

[14] Santelli JS, Lowry R, Leah R. The association of sexual behaviours with socio economic status, family structure, and race/ethnicity among US adolescents. Am J Public Health 2000; 90 (10): 1582-88.

[15] Adler NE, Ostrove JM. Socioeconomic status and health. What we know and what we don't. Ann NY Acad sci. 1999; 896: 3-15. 